\title{
Târîhu Meyyâfârikīn
}

İbnü'l-Ezrak el-Fârikī, nşr. Kerîm Fârûk el-Hûlî-Yusuf Baluken

İstanbul: Nûbihar Yayınları, 2014, 701 sayfa.

ISBN 9786055053352

Abbâsîler, Mâverâünnehir'den Endülüs'e, Kafkasya'dan Yemen’e kadar Emevîler'den tevarüs ettikleri bölgeleri hâkimiyetleri altında bulundurmuşlardır. Ancak zamanla merkezî hilafetin bünyesinde yaşanan iktidar mücadeleleri ve büyük bir coğrafyaya yayılan devleti tek merkezden idare etmenin getirdiği zorluklar II. (VIII.) asrın ortalarından itibaren farklı bölgelerde bağımsız veya yarı bağımsız hanedanların ortaya çıkmasına zemin hazırlamıştır. Özellikle IV. (X.) asırdan itibaren yoğun bir şekilde ortaya çıkan ve bir kısmı devletin yıkılışına kadar varlığını devam ettiren bu hanedanlar, siyasî ve idarî açıdan kurdukları düzenlerini devam ettirmişler ve zaman zaman Abbâsîler'e karşı bir tavır içerisinde olmaktan da geri durmamışlardır. Bu noktada söz konusu hanedanların siyasî ve idarî faaliyetleriyle başta Abbâsî halifeliği olmak üzere diğer hanedanlarla kurdukları ilişkiler Abbâsî tarihini merkeze alan tarih kaynaklarında nispeten daha az yer almıştır. Dolayısıyla Abbâsîler'in hâkim olduğu merkezî Irak toprakları dışındaki bölgelerle ilgili araştırma yapmak isteyenlerin bu hanedanların tarihinden bahseden kaynaklara başvurmaları gerekmektedir.

İbnül-Ezrak el-Fârikỉnin (ö. 577/1181'den sonra) kitabı 372-478 (9831085) yılları arasında Meyyâfârikīn (Silvan) merkez olmak üzere Diyarbekir (Âmid) ve çevresinde hüküm süren Mervânîler'le, 495-812 (1102-1409) yılları arasında yine aynı bölgeye hâkim olan Artuklular’ın (Mardin kolu) erken dönemi açısından kıymetli bir eserdir. Zira İbnüll-Ezrak’ın, idarî açıdan dönemin önde gelen bazı kişileriyle yaptığı görüşmelere ve bir süre Diyarbekir (Âmid) valiliği ve Sultan Melikşah (465-485/1072-1092) nezdinde elçilik yapan dedesi Reîs Ebü'l-Hasan Ali b. el-Ezrak’ın şahit olduğu olaylarla ilgili babasının anlattıklarına dayanarak bilgi vermesi söz konusu eserin VI. (XII.) asır Irak ve el-Cezîre coğrafyası için vazgeçilmez bir kaynak olduğunu göstermektedir. Nitekim İbnü'l-Ezrak, Ukaylîler, Mirdâsîler ve Mervânîler gibi bazı emirliklerle Abbâsîler ve Büyük Selçuklular gibi devletlerde birtakım idarî görevler üstlenen Benî Cehîr ailesinin de içinde yer aldığı hadiseler ve yine bu ailenin Büyük Selçuklular’ın hizmetinde bulunduğu sırada Diyarbekir (Âmid) üzerine sefer düzenlemesi, akabinde de Mervânîler'in yıkılmasıyla sonuçlanan olaylar hakkında dedesinin gözlemlerine dayanarak ayrıntılı bil- 
giler sunmuştur. Bunların dışında Müsterşid-Billâh (512-529/1118-1135) ve Râşid-Billâh (529-530/1135-1136) dönemlerinde Dîvânü'l-inşâda kâtiplik yapan ve bir defa da vezirliğe vekâlet (nâibülvezir) eden Sedîdüddevle Muhammed b. el-Enbârî ile (İbnü’l-Enbârî) görüşerek onun aktardığı bazı bilgilere yer vermiştir. Mesela kitapta Müsterşid-Billâh’ın Sultan Mesud’a karşı gerçekleştirdiği, ancak başarısızla sonuçlanan savaşın hemen öncesinde halifenin, aralarında İbnü'l-Enbârînin de bulunduğu, devlet adamlarıyla yaptığı istişarenin detaylarıyla ilgili bilgiler aktarılmıştır. Bu sırada halifeyle yakın çevresi arasında yaşananlar hakkında en erken kayıtların İbn Vâsıl (ö. 697/1298) ve İbnü̉d-Devâdârî (ö. 736/1336'dan sonra) gibi geç dönem müelliflerinin eserlerinde yer alması, İbnü'l-Ezrak'ın kitabının kıymetini daha da arttıran unsurlar olarak değerlendirilebilir.

Yukarıda bazı örneklerine işaret edilen hususlardan dolayı Sıbt İbnü'lCevzî (ö. 654/1256), İbnü’l-Adîm (ö. 660/1262), İbn Hallikân (ö. 681/1282) ve Zehebî (ö. 748/1348) gibi müellifler hem Mervânîler hem de Selçuklular'la ilgili konularda İbnü'l-Ezrak’tan bazı nakillerde bulunmuşlardır.

Kitabını üç ciltten oluşan bir dünya tarihi olarak kaleme alan İbnüllEzrak’ın eserinin I. cildi yaratılıştan Hz. Peygamber dönemine kadar, II. cildi Hz. Peygamber dönemini, III. cildi ise Hulefâ-yi Râş̧idîn döneminden başlayıp müellifin yaşadığı döneme kadar olan süreyi kapsamaktadır. Ancak eserin ilk iki cildi günümüze ulaşmamıştır. İlim dünyasına varlığı ilk defa Heinrich Ferdinand Wüstenfeld (1808-1899) tarafından duyurulan İbnü'l-Ezrak'ın kitabı V.F. Minorsky (1877-1966) ve H.F. Amedroz’un (1854-1917) çalışmaları sayesinde daha da tanınır hale gelmiş ve zaman içinde eserin kısmî neşirleriyle İngilizce, Türkçe ve Rusça kısmî tercümeleri yapılmıştır.

Eserin Mervânîler'le ilgili kısmını içeren ilk neşri Bedevî Abbüllatif Avad tarafından gerçekleştirilmiş ve Târîhu'l-Fâriki: ed-Devletüll-Mervâniyye adıyla kitap olarak yayımlanmıştır (Kahire 1959). Ahmet Savran da eserin Artuklular'la ilgili kısmını Târihu Meyyâfârikīn ve Âmid: Kısmü'l-Artukıyyîn) adiyla doktora tezi olarak neşretmiştir (Erzurum 1987). Carole Hillenbrand ise Savran'ın neşrini gerçekleştirdiği bölümün Artuklu emîrleri Necmeddin İlgazi (502-516/1108-1122) ve Hüsâmeddin Timurtaş (516-548/1122-1153) dönemleriyle ilgili kısmını İngilizce tercümesiyle birlikte A Muslim Principality in Crusader Times: The Early Artuqid State başlığıyla yayımlamıştır (İstanbul 1990). Bunların dışında Chase Robinson ${ }^{1}$ İbnü’l-Ezrakı̀n eserinin o ana kadar neşredilmemiş olan ilk 120 varakının muhtevasını ana hatlarıyla

1 Robinson, "Ibn al-Azraq", s. 7-27. 
İngilizce’ye tercüme etmiş ve buradan hareketle İbnü’l-Ezrakın kaynakları ve Hz. Ali yanlısı olduğu meselesi üzerinde durmuştur.

Kerîm Fârûk el-Hûlî ve Yusuf Baluken ise Avad ve Savran’n neşrettikleri bölümlerle, henüz yazma halinde bulunan Mervânîler'den önceki kısımları da dahil ederek İbnü'l-Ezrak’ın eserinin III. cildinin tamamını Târîhu Meyyâfârikin adıyla yayımlamışlardır. Dolayısıyla elimizde bulunan bu neşir Hz. Ömer'in halifeliğinin ilk yıllarından (14/635) Selâhaddîn-i Eyyûbî̉nin Haçlılar'la mücadele ettiği döneme kadar (572/1176-1177) olan süreyi kapsamaktadır.

Nâşirlerden Hûlî tarafından kaleme alınan giriş kısmının birinci bölümünde, önce eserin iki yazma nüshası (muhtasar ve mufassal) kısaca tanıtılmış, müellif veya müstensih tarafından yapılan yazım hatalarından örnekler verilmiş, ardından Avad ve Savran’ın neşirlerindeki bazı yanlışlardan bahsedilmiştir (s. 5-17). İkinci bölümde ise İbnüll-Ezrak’n hayatı, mezhebî aidiyeti, eserini telif etmesinin sebebi, yazıll, şifahî ve görsel kaynakları, kaynak kullanım şekli, rivayetleri aktarırken yaptığı hatalar, İbnü’l-Ezrak’tan istifade eden müellifler ve eserin önemi üzerinde durulmuştur (s. 19-79). Uzun sayılabilecek bir giriş kaleme almış olmasına rağmen Hûlînin zikrettiği hususların, Minorsky ve Amedroz'un çalışmalarına dayanan Avad, Savran, Hillenbrand ve Robinson gibi araştırmacıların verdiği bilgilerle hemen hemen aynı mahiyette olduğu söylenebilir. Ancak konular ele alınırken benzer meselelerle ilgili önceki araştırmacıların yorum ve değerlendirmelerine herhangi bir atıfta bulunulmamış olması, söz konusu çalışmanın mevcut literatüre katkısına gölge düşürmüştür.

Konuyla ilgili zikredilmesi gereken bir diğer husus eserin isminin Târîhu Meyyâfârikin olarak tercih edilmesidir. Bilindiği üzere mevcut nüshaların baş ve son taraflarındaki bazı varaklar kaybolmuş, bundan dolayı araştırmacılar eserin adı üzerinde tam bir ittifak sağlayamamıștır. Muhtemelen nüshalarla ilgili bu durumu dikkate alan Avad eseri Târîhhu'l-Fârikî ismiyle neşretmiştir. Savran ise İbnüll-Ezrak’ın eserinin üçte birlik kısmını istinsah eden ve Oxford Üniversitesi Bodleian Kütüphanesi’nde Marsh 333 numarasılla kayıtlı bulunan yazmanın adı meçhul müellifinin² İbnül-Ezrakı Târîhu Meyyâfârikìn ve Âmid'in müellifi olarak zikretmesinden hareketle o da eserin ismini Târîhu Meyyâfârikin ve Âmid olarak kabul etmiştir. ${ }^{3}$ Bu noktada Hûlî ve Baluken,

2 Amedroz ve Minorsky bu müellifin Eyyûbi dönemi tarihçisi el-A 'lâku'l-hatîre adlı eserin müellifi İzzeddin İbn Şeddâd olduğu kanaatindedir (bk. Amedroz, "Three Arabic MSS. on the History", s. 801; Minorsky, "Meyyâfârikîn”, s. 200).

3 Savran, “Giriş”, s. 53. 
İbnü'l-Ezrak ve eseriyle ilgili bilgi veren bazı kaynaklara atıf yapmakla birlikte (s. 64-66) bu üçüncü nüshadan bahsetmedikleri gibi İbnü'l-Ezrak’n eserinin ismini neden Târîhu Meyyâfârikin olarak tercih ettiklerine dair herhangi bir gerekçe de sunmamışlardır.

İbnü'l-Ezrak’in eserinin istinsah tarihi ve kim tarafından istinsah edildiği de araştırmacılar arasında tartışılan konulardan biridir. Şöyle ki, Şevval 510 (Şubat 1117) tarihinde doğan İbnül-Ezrak'in 577'den (1181) sonra vefat ettiği kabul edilmektedir. Ancak kitapta 500 (1107) yılına kadar Abbâsî halifelerinin adlarının ve hilafet sürelerinin verildiği listede son Abbâsî halifesi Müsta'sım-Billâh’’n da (640-656/1242-1258) adı zikredilmektedir (s. 342348). Bu da mevcut nüshaların en erken VII. (XIII.) asrın ikinci yarısında ve müellifin dışında başka bir kişi tarafından istinsah edildiğini göstermektedir. Avad ve Savran metinde Arapça dil bilgisi ve basit imla hatalarından dolayı müstensihin Arapça’ya âşina olmayan bir Türk kâtip olduğunu iddia etmektedir. ${ }^{4}$ Ancak Avad’n eserinin neşri münasebetiyle bir değerlendirme yazısı kaleme alan Sevim ise metinde yer alan Türkçe kelimelerin yanlış yazıldığından hareketle, müstensihin Türk asıllı olmadığına dair bir imada bulunmaktadır. ${ }^{5}$ Bu konuda daha temkinli davrandığı anlaşılan Hûlî ise Arapça ifadelerin yazımındaki bazı hatalardan örnekler sunmakla birlikte, müstensihin menşeine dair herhangi bir açıklama yapmamış, dahası bu durumun müellifin yaşadığı dönemde Irak ve el-Cezîre coğrafyasında Arapçảnın diğer dillerle etkileşiminin bir sonucu olduğunu söylemiştir (s. 8-10).

Yukarıda zikredildiği üzere İbnüll-Ezrak ve eseri üzerinde yapılan çalışamalara herhangi bir şekilde temas etmeyen Hûlî ve Baluken'in, Sevim'in yazma nüshadaki bazı okuma "hatalarına" dair Avad'a yönelttiği tenkit ve teklifleri de dikkate almadıkları görülmektedir. Mesela Sevim, mufassal nüshada Kāim-Beimrillâh (422-467/1031-1075) dönemindeki Selçuklu emîrlerinden Atsız b. Uvâk'tan bahseden bir yerde, her ikisinin de neredeyse noktaları silinmiş bir halde جبل قنق kelimelerinin yer aldığını, ancak Avad'ın ${ }^{6}$ sadece kelimesini metne dahil ettiğini söylemekte, kendi tercihinin ise Atsız’n Türkmen olması sebebiyle ve ifadenin siyak ve sibakına göre جيل قنت (Kınık boyundan) şeklinde okunması gerektiğini belirtmektedir. ${ }^{7}$ Hûlî ve Baluken ise ifadeyi tamamen farklı bir şekilde ve herhangi bir açıklama yapmayarak ş şبل فيق fassal nüshada الكوهباري olarak yazılan kişi Selçuklular’n Bağdat şahneliğini

4 Avad, "Mukaddime", s. 5-6; Savran, "Giriş", s. 54-55.

5 Sevim, “Tarihü Meyyâfârikîn”, s. 177.

6 İbnül-Ezrak, Târîhu'l-Fârikī, s. 192.

7 Sevim, “Tarihü Meyyâfârikîn”, s. 188-89. 
yapan Sa'düddevle Gevherâyîn'dir (ö. 493/1100). ${ }^{8}$ Aslında Avad metnin ilgili kısmında bu kişinin Gevherâyîn olduğuna dair diğer kaynaklarda geçen ifadelere atıfta bulunmuştur. ${ }^{9}$ Ancak Hûlî ve Baluken ise kelimenin muhtasar nüshadaki yazılışını zikretmekle yetinmiş, bu kişinin kim olduğuna dair herhangi bir açıklama yapmamıştır (s. 520). Sevim' in işaret ettiği bir diğer hususa göre İbnü’l-Ezrak, Belih çayı savaşında Haçlılar’a karşı büyük bir galibiyet elde eden Hasankeyf Artuklu Beyliğinin kurucusu Emîr Sökmen b. Artuk’un ismiyle Ahlatşahlar hanedanının kurucusu Sökmen el-Kutbîyi birbirine karıştırmış ve savaşın tarihini, İbnüll-Esîr ${ }^{10}$ ve diğer pek çok kaynakta Şâban 497 (Nisan-Mayıs 1104) olarak aktarıldığı halde 499 (1105-1106) olarak zikretmiştir. ${ }^{11}$ Avad ise bu hususlara hiç değinmemiştir. Hûlî ve Baluken ise dipnotta bu olayın İbn Şeddâd (ö. 684/1285) tarafından aktarıldığını belirtmiş, ancak Sevim'in işaret ettiği noktalarla ilgili herhangi bir açıklama yapmamıştır (s. 547). Yine benzer şekilde Suriye Selçuklu Sultanı Tutuş̧un vefat tarihiyle ilgili İbnü’l-Ezrak’ın zikrettiği 506 (1111-1112) yılı, hem Avad hem de Hûlî ve Baluken tarafından olduğu gibi kabul edilmiştir (s. 549). Ancak Hûlî ve Baluken'in, bu olayla ilgili atıfta bulundukları İbnü'l-Esîr ${ }^{12}$ başta olmak üzere hemen bütün kaynaklar Tutuş’un, amcası Sultan Berkyaruk'la 17 Safer 488 (26 Şubat 1095) tarihinde Rey yakınlarında yaptığg savaşta yenildiğini, akabinde de öldürüldüğ̈nü belirtmektedir. ${ }^{13}$

Sonuç itibariyle İbnüll-Ezrak’ın kitabının yeni neşrinin önceki yayınların eksik bıraktığı kısımları ihtiva etmesi sebebiyle önemli bir boşluğu doldurması beklenmektedir. Ayrıca zaman zaman dipnotlarda açıklayıcı bilgiler verilmesi ve kitabın sonunda detaylı bir indeksin bulunması eserden daha çok istifade imkânı sunmaktadır. Bununla birlikte Avad ve Savran’ın aksine metnin başlıklandırılması konusunda nispeten külfetsiz davranıldığı görülmektedir. Yine metnin sonunda neşir sırasında kullanılan eserlerin bibliyografik künyelerini ihtiva eden bir listenin verilmemesi ve okunuşunda yanlış anlaşılmalara sebebiyet verebilecek garip kelimelerle isimlere hareke konulmaması dikkat çeken bir eksiklik olarak zikredilmelidir.

8 Sevim, “Tarihü Meyyâfârikîn” s. 189.

9 İbnü'l-Ezrak, Târîhu'l-Fârikī, s. 211, dn. 3 .

10 İbnü'l-Esîr, herhangi bir ay belirtmeksizin savaşı 497 (1103-1104) yılı olayları içinde zikretmektedir (el-Kâmil, X, 373-74). Yine Sevim'in atıfta bulunduğu İbnü'l-Adîm söz konusu savaşın 496 (1102-1103) y1lında (Zübdetül-haleb, II, 148), Urfalı Mateos ise Ermeni takvimine göre 554 yani 498 (1104-1105) yllında gerçekleştiğini ifade etmektedir (Urfalı Mateos Vekayi-nâmesi, s. 226).

11 Sevim, “Tarihü Meyyâfârikîn” s. 192.

12 İbnü'l-Esîr, el-Kâmil, X, 244-45. Ayrıca bk. İbnü'l-Cevzî, el-Muntazam, XVII, 19.

13 Sevim, “Tarihü Meyyâfârikîn” s. 192-93. 


\section{Bibliyografya}

Amedroz, H. F., "Three Arabic MSS. on the History of the City of Mayyāfäriqīn”, The Journal of the Royal Asiatic Society of Great Britain and Ireland, 4 (1902): 785-812.

Avad, Bedevî Abdüllatîf, “Mukaddime”, İbnü'l-Ezrak el-Fârikī, Târîhu’l-Fârikī: ed-DevletüllMervâniyye içinde, s. 1-47.

İbnü'l-Adîm, Zübdetü’l-haleb fî târîhi Haleb, nşr. Sâmî ed-Dehhân, I-III, Dımaşk: Institut Français de Damas, 1951-68.

İbnü'l-Cevzî, Ebü'l-Ferec, el-Muntazam, nşr. M. Abdülkādir Atâ - Mustafa Abdülkādir Atâ, I-XVIII, Beyrut: Dârül-kütübi'l-ilmiyye, 1412/1992.

İbnü'l-Esîr, İzzeddin, el-Kâmil fi't-târîh, nşr. C. J. Tornberg, I-XIII, Beyrut: Dâru Sâdır Dâru Beyrut, 1965.

İbnü’l-Ezrak el-Fârikī, Târîhu'l-Fârikī: ed-Devletü'l-Mervâniyye, nşr. Bedevî Abdüllatîf Avad, Kahire: el-Hey'etü’l-âmme li-şuûni'l-metâbii'l-emîriyye, 1379/1959.

İbnü'l-Ezrak el-Fârikī, Târîhu Meyyâfârikīn ve Âmid: Kısmül-Artukıyyîn, nşr. Ahmet Savran (doktora tezi), Atatürk Üniversitesi, Erzurum, 1987.

Minorsky, V., “Meyyâfârikîn”, İA, VIII, 196-201.

Robinson, Chase, “Ibn al-Azraq, His ‘Ta’rìkh Mayyāfäriqīn', and Early Islam”, Journal of the Royal Asiatic Society, 1 (1996): 7-27.

Savran, Ahmet, “Giriş", İbnü’l-Ezrak el-Fârikī, Târîhu Meyyâfârikīn ve Âmid: KısmülArtukıyyîn içinde, s. 51-80.

Sevim, Ali, “Tarihü Meyyâfârikîn ve Âmid’in Mervanlılar Bölümü’nün Yayını Münasebetiyle", TTK Bildiriler, 6 (1967): 172-96.

Urfalı Mateos Vekayi-nâmesi (952-1136) ve Papaz Grigor’un Zeyli (1136-1162), nşr. ve çev. H. D. Andreasyan, Ankara: Türk Tarih Kurumu Yayınları, 2000.

Halil İbrahim Hançabay, Dr.Öğr. Üyesi İstabul Üniversitesi İlahiyat Fakültesi

ORCID 0000-0002-0387-0824

DOI 10.26570/isad.571969 